DISTRIBUTION STATEMENT A. Approved for public release; distribution is unlimited.

\title{
Evaluating the Effects of Stressors on Immune Function during Simulated Dives in Marine Mammals
}

\author{
Tracy Romano, PhD \& Laura Thompson, PhD Candidate \\ Mystic Aquarium \\ A division of Sea Research Foundation \\ 55 Coogan Blvd. \\ Mystic, CT 06355 \\ phone: (860) 572-5955 ext.102 fax:(860) 572-5969 email: tromano@mysticaquarium.org \\ phone: (860) 572-5955 ext. 155 fax:(860)572-5969 email: 1thompson@mysticaquarium.org
}

Award Number: N00014-13-1-0768

http://searesearch.org

\section{LONG-TERM GOALS}

The major goals of this study were to 1) gain an understanding of the marine mammal immune response with respect to dive adaptation by investigating the response of marine mammal immune cells to simulated dives (i.e. pressure excursions) and 2) to evaluate the potential for additional stressors to alter the response of marine mammal immune cells to simulated dives, thereby providing information which may aid future efforts to assess the impacts of anthropogenic activities on marine mammal health.

\section{OBJECTIVES}

The specific objectives of this effort were to 1) investigate the effects of simulated dive exposures on cellular immune function in belugas, 2) evaluate the effects of simulated dive exposures on cellular immune function in belugas following a known stressor event, 3) collect biological samples from wild belugas to compare with aquarium whales, and 4) compare the effects of simulated dive exposures on cellular immune function in seals from stranding (stressor) and release (healthy).

\section{APPROACH}

Tracy Romano was the P.I. for the project and the primary mentor of Laura Thompson, the graduate student who carried out the project for her PhD thesis. She oversaw all aspects of this project. Laura Thompson recently completed her PhD at the University of Connecticut (UCONN), Department of Marine Biosciences and this work served as a major component of her dissertation research.

For all objectives, simulated pressure excursions (dives) were performed in vitro by introducing blood samples to a benchtop stainless steel pressure chamber, brought to the desired pressure by manual addition of mineral oil via hydraulic pump.

To fulfill objectives 1 and 2, blood samples were collected from four belugas (Delphinapterus leucas), at the Mystic Aquarium, Mystic, CT. Baseline sampling was done using positive behavioral 


\section{Report Documentation Page}

Form Approved

OMB No. 0704-0188

Public reporting burden for the collection of information is estimated to average 1 hour per response, including the time for reviewing instructions, searching existing data sources, gathering and maintaining the data needed, and completing and reviewing the collection of information. Send comments regarding this burden estimate or any other aspect of this collection of information,

including suggestions for reducing this burden, to Washington Headquarters Services, Directorate for Information Operations and Reports, 1215 Jefferson Davis Highway, Suite 1204, Arlington

VA 22202-4302. Respondents should be aware that notwithstanding any other provision of law, no person shall be subject to a penalty for failing to comply with a collection of information if it

does not display a currently valid OMB control number.

1. REPORT DATE

30 SEP 2014

4. TITLE AND SUBTITLE

Evaluating the Effects of Stressors on Immune Function during Simulated Dives in Marine Mammals

6. AUTHOR(S)

7. PERFORMING ORGANIZATION NAME(S) AND ADDRESS(ES)

Mystic Aquarium,A division of Sea Research Foundation,55 Coogan Blvd,Mystic,CT,06355

9. SPONSORING/MONITORING AGENCY NAME(S) AND ADDRESS(ES)
3. DATES COVERED

00-00-2014 to 00-00-2014

5a. CONTRACT NUMBER

5b. GRANT NUMBER

5c. PROGRAM ELEMENT NUMBER

5d. PROJECT NUMBER

5e. TASK NUMBER

5f. WORK UNIT NUMBER

8. PERFORMING ORGANIZATION

REPORT NUMBER

10. SPONSOR/MONITOR'S ACRONYM(S)

11. SPONSOR/MONITOR'S REPORT

$\operatorname{NUMBER}(S)$

12. DISTRIBUTION/AVAILABILITY STATEMENT

Approved for public release; distribution unlimited

13. SUPPLEMENTARY NOTES

14. ABSTRACT

15. SUBJECT TERMS

16. SECURITY CLASSIFICATION OF: a. REPORT

unclassified b. ABSTRACT unclassified c. THIS PAGE

unclassified
17. LIMITATION OF ABSTRACT

Same as

Report (SAR)
18. NUMBER 19a. NAME OF

OF PAGES

7 
reinforcement to greatly minimize the potential for sampling stress to confound results. In order to carry out a species comparison with a non-dive adapted mammal, human blood samples were purchased from Biological Specialty Corporation (www.biospecialty.com). Under a prior ONR effort (N00014-11-1-0437) 'stressor' samples were obtained from three whales (1 male, 2 females) at the conclusion of a $30 \mathrm{~min}$ OWE, prior to being returned to the water. To look at the effects of individual hormones (objective 2) isoproterenol and hydrocortisone were purchased from Sigma-Aldrich. In vitro incubations with each hormone will be carried out prior to immune function assays. The addition of blockers will be used to verify the direct effects of each hormone.

To fulfill objective 3, blood samples were obtained from belugas in Bristol Bay, AK during live capture health assessment efforts in late summer 2012 (NMFS Marine Mammal Research Permit No. 14245). Blood samples were initially processed in the field and shipped back to Mystic Aquarium in LN dry shippers for hormone analyses and immune function assays. PBMC activation (IL2R expression) and proliferation were carried out with and without pressure exposures.

To fulfill objective 4, blood samples were collected opportunistically from stranded pinnipeds admitted to the Marine Mammal Rehabiltation Program at Mystic Aquarium, including harbor seals (Phoca vitulina) grey seals ( Halichoerus grypus) and harp seals (Phoca groenlandica). Samples were obtained once at the time of admit ('stressed') and again pre-release ('healthy'). Epinephrine and norepinephrine, as well as cortisol, were measure in plasma. Immune function assays were carried out as in aims 1, 2 and 3.

\section{Immune Function Assays}

Granulocyte and monocyte phagocytosis were measured using methodology detailed in Spoon and Romano (2012) and modified to include pressure excursions. Briefly, blood samples were incubated with propidium labeled killed Staphylococcus aureus (PI Staph) at a bacteria:cell ratio of 25:1, and flow cytometry was used to measure the uptake of bacteria by cells.

Neutrophil and PBMC activation were assessed by measuring expression of CD11b and IL2R, respectively using commercially available reagents (mouse anti canine CD11b antibody, AbDserotec, Raleigh, NC; Human Fluorokine IL2Kit, R\&D systems, Minneapolis, MN). In both cases, cells are incubated with fluorescently labeled antibodies and flow cytometery was used to detect binding and thus expression.

Lymphocyte proliferation was measured using a commercially available cell proliferation ELISA assay (Roche Diagnostics, Indianapolis, IN). Isolated mononuclear cells were incubated for $72 \mathrm{hrs}$ with concanavlin A in order to induce proliferation. Bromodeoxyuridine (BrdU), a thymidine analog, was added, and cells were fixed, lysed and labelled accoriding to kits instructions. Results were read colorimetrically using a microplate spectrophotometer (BioTek Instruments, Winooski, VT) and a proliferation index was calculated.

\section{Hormone Analyses}

Plasma cortisol was determined by Immulite ${ }^{\circledR}$ chemiluminescent assay at the Animal Health Diagnostic Center, Endocrinology Lab at Cornell University (Ithaca, NY). Plasma catecholamines were measured in house at the Mystic Aquarium using a Waters (Milford, MA) High Performance Liquid Chromotography system(1515 isocratic pump, 717 autosampler) with Electrochemical Detection (2465 electrochemical detector) following the methodology detailed in "Plasma Catecholamines by HPLC" (Instruction Manual, June 2001, BIO-RAD, Hercules, CA). 


\section{WORK COMPLETED}

Objective 1: All work for objective 1 has been completed. Phagocytosis, cell activation and lymphocyte proliferation were measured in both belugas and humans following all targeted dive profiles. Exposures targeted two pressures [2000 psi $(1360 \mathrm{~m})$ and 1000 psi $(680 \mathrm{~m})]$, with a period of either 2 minutes $(\mathrm{G})$ or 15 seconds $(\mathrm{R})$ for compression and decompression. Exposures lasted for 30 minutes, 5 minutes or two repeated sessions of 5 minutes each. Catecholamines and cortisol were also measured in each sample.

Objective 2: An out of water examination was completed for three whales ( 1 males, 2 females) with blood samples obtained following the 30 minute procedure, prior to returning the animals to the water. Immune Function assays were carried out with and without pressure exposures to 2000G.

Catecholamines and cortisol were measured in each sample.

In addition, opportunistic blood samples were obtained during clinical health checks on two animals which presented with clinical signs of chronic mild inflammation of the fluke vessels. Pressure exposures to $2000 \mathrm{G}$ and $1000 \mathrm{G}$ were completed. Catecholamines and cortisol were also measured.

Objective 3: Blood samples were obtained from 9 wild belugas from the Bristol Bay, AK population during live capture health assessment efforts in 2012. Catecholamines and cortisol analyses have been completed. PBMC activation and lymphocyte proliferation were measured with and without exposures to $2000 \mathrm{G}$ for all animals.

\section{Objective 4:}

Blood samples were obtained from stranded pinnipeds admitted to the Mystic Aquarium Marine Mammal Rehabilitation Program, as opportunity and animal conditions allowed. Pressure exposures to 2000G were completed. Paired admit and release samples were obtained from 6 animals.

\section{RESULTS}

Results for all immune functions measured, for all pressure exposures are summarized in Table 1.

\section{Objective 1: Investigate the effects of simulated dive exposures on cellular immune function in belugas}

Overall, belugas cells displayed decreased phagocytosis following pressure exposures, with values returning to control levels or increasing following a recovery period, though these changes varied depending on the pressure exposure (i.e. with depth, compression and decompression period and length of exposure). Results from exposures to 1000R were the most different from all other exposures. In contrast, human cells tended to display either smaller decreases, or increases, in phagocytic activity following pressure exposures. 
Table 1: Summary of results for all immune function responses following all pressure exposures. No color=no significant change, Red=significant decrease in function following exposures, Yellow=significant increase in function following exposures $(\alpha=0.05)$. Hashmarks indicate a trend where $\alpha<0.1$.

\begin{tabular}{|c|c|c|c|c|c|c|c|c|c|c|c|c|c|c|c|c|}
\hline & \multirow{4}{*}{\multicolumn{2}{|c|}{$\begin{array}{l}\text { No change } \\
\text { Decrease } \\
\text { Increase } \\
\text { Irend }\end{array}$}} & & \multicolumn{8}{|c|}{ Phagocytosis } & \multirow{2}{*}{\multicolumn{2}{|c|}{ CD11b Expression }} & \multirow{2}{*}{\multicolumn{2}{|c|}{ II2R Expression }} & \multirow{3}{*}{\begin{tabular}{|l|} 
Proliferation \\
T Lymphocyte \\
\end{tabular}} \\
\hline & & & & \multicolumn{4}{|c|}{ Dive } & \multicolumn{4}{|c|}{ Recovery } & & & & & \\
\hline & & & & \multicolumn{2}{|c|}{ Granulocytes } & \multicolumn{2}{|c|}{ Monocytes } & \multicolumn{2}{|c|}{ Granulocytes } & \multicolumn{2}{|c|}{ Monocytes } & \multicolumn{2}{|c|}{ Granulocytes } & \multicolumn{2}{|c|}{ PBMC } & \\
\hline & & & & MFI & $\%$ & MFI & $\%$ & MFI & $\%$ & MFI & $\%$ & MFI & $\%$ & MFI & $\%$ & Index \\
\hline \multirow{18}{*}{$2000 \mathrm{G}$} & \multirow{6}{*}{$30 \mathrm{~min}$} & \multirow{3}{*}{ Beluga } & Baseline & & & & & & & & & & & & & \\
\hline & & & OWE & & & & & & & & & & & & & \\
\hline & & & Bristol Bay & & & & & & & & & & & & & \\
\hline & & \multicolumn{2}{|l|}{ Humans } & & & & & & & & & & & & & \\
\hline & & \multirow{2}{*}{ Phocids } & Admit & & & & & & & & & & & & & \\
\hline & & & Release & & & & & & & & & & & & & \\
\hline & \multirow{6}{*}{$5 \mathrm{~min}$} & \multirow{3}{*}{ Beluga } & Baseline & & & & & & & & & & & & & \\
\hline & & & OWE & & & & & & & & & & & & & \\
\hline & & & Bristol Bay & & & & & & & & & & & & & \\
\hline & & Humans & & & & & & & & & & & & & & \\
\hline & & Phocids & Admit & & & & & & & & & & & & & \\
\hline & & Pliocias & Release & & & & & & & & & & & & & \\
\hline & & & Baseline & & & & & & & & & & & & & \\
\hline & & Beluga & OWE & & & & & & & & & & & & & \\
\hline & $2 \times 5 \mathrm{~min}$ & & Bristol Bay & & & & & & & & & & & & & \\
\hline & 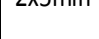 & Humans & & & & & & & & & & & & & & \\
\hline & & Phocids & Admit & & & & & & & & & & & & & \\
\hline & & Pliocias & Release & & & & & & & & & & & & & \\
\hline & $30 \mathrm{~min}$ & Beluga & Baseline & & & & & & & & & & & & & \\
\hline & corimen & Humans & & & & & & & & & & & & & & \\
\hline $1000 \mathrm{G}$ & $5 \mathrm{~min}$ & Beluga & Baseline & & & & & & & & & & & & & \\
\hline 10000 & . & Humans & & & & & & & & & & & & & & \\
\hline & $2 \times 5 \mathrm{~min}$ & Beluga & Baseline & & & & & & & & & & & & & \\
\hline & $2 \times 5 \mathrm{~min}$ & Humans & & & & & & & & & & & & & & \\
\hline & $30 \mathrm{~min}$ & Beluga & Baseline & & & & & & & & & & & & & \\
\hline & ormint & Humans & & & & & & & & & & & & & & \\
\hline 20001 & $5 \mathrm{~min}$ & Beluga & Baseline & & & & & & & & & & & & & \\
\hline & & Humans & & & & & & & & & & & & & & \\
\hline & $2 \times 5 \mathrm{~min}$ & Beluga & Baseline & & & & & & & & & & & & & \\
\hline & $2 \times 30101$ & Humans & & & & & & & & & & & & & & \\
\hline & $30 \mathrm{~min}$ & Beluga & Baseline & & & & & & & & & & & & & \\
\hline & . & Humans & & & & & & & & & & & & & & \\
\hline $1000 R$ & $5 \mathrm{~min}$ & Beluga & Baseline & & & & & & & & & & & & & \\
\hline $1000 \mathrm{~K}$ & (1) & Humans & & & & & & & & & & & & & & \\
\hline & $2 x$ & Beluga & Baseline & & & & & & & & & & & & & \\
\hline & | LAJTाIII & Humans & & & & & & & & & & & & & & \\
\hline
\end{tabular}

Few significant changes in CD11b expression were detected in either humans or belugas following pressure exposures, though the response varied with exposure. However, following exposures to 1000R belugas displayed significant increases in CD11b expression, while humans displayed decreases.

Both belugas and humans displayed increased measures of IL2R expression, suggesting activation of PBMC's. In contrast, lymphocyte proliferation decreased in belugas following pressure exposures, while humans displayed no changes or increases following exposures to 2000psi. 
Decreased immune function following pressure exposures in beluga was unexpected, but differed from the response of humans and thus may reflect cellular adaptation and reduced likelihood of damage from inflammatory processes. Values were returned to control levels suggesting the effects of a dive are not long lasting. That results for belugas varied between pressure exposures (e.g. 2000G vs. $1000 \mathrm{G})$ also suggests dive characteristics (e.g. depth, duration) play important roles in determining immune function indicating there could be some plasticity to the response as with other aspects of mammalian dive physiology.

\section{Objective 2: evaluate the effects of simulated dive exposures on cellular immune function in belugas following a known stressor event}

Hormone data supports the OWE as a 'stressor' as expected. Hormone values obtained from samples during a period of inflammation are similar to values obtained from baseline samples. Control measure of immune function (i.e. without pressure exposures) also suggested altered function during stressor conditions as compared with baseline.

Both OWE and inflammation samples displayed general patterns of granulocyte phagocytosis similar to baseline samples; decreased phagocytic activity for the dive periods of pressure exposures, with increased activity following the further recovery period. OWE samples however, displayed a much larger change than baseline during these recovery periods. For inflammation samples, monocyte phagocytosis displayed patterns suggesting increased function following pressure exposures. Also similar to baseline conditions, no significant changes in CD11b expression were detected. However, the changes which were observed were larger in both OWE and inflamation samples, than those measured in baseline samples.

IL2R expression in stressor samples increased following pressure exposures, whereas lymphocyte proliferation decreased. Again the change in IL2R expression was larger for OWE conditions as compared with baseline.

As with baseline conditions, the response of cells to pressure exposures varied with the duration. In some cases the changes occuring in OWE or inflammation samples were more similar to those observed in humans than in baseline conditions. Thus, responses occurring in belugas during stressor conditions are different from those which occur under baseline conditions suggesting there could be sub-lethal consequences on animal health.

Objective 3: To collect biological samples from wild belugas to compare with aquarium animals Plasma hormone values for Bristol Bay animals were higher than those measured in aquarium belugas, though cortisol was similar to OWE samples. Control values (without pressure exposure) of both IL2R expression and lymphocyte proliferation were lower in Bristol Bay animals as compared with either baseline or OWE samples for aquarium animals.

IL2R expression displayed general patterns of pressure-induced increases, similar to aquarium animals. However, where aquarium animals displayed a contradictory decrease in proliferation, Bristol Bay belugas displayed increased proliferation. These changes were smaller than the changes seen in either baseline or OWE conditions in aquarium belugas and appear more similar to the response measured in humans.

Differences in the lymphocyte response to pressure between the Bristol Bay animals and aquarium animals (both baseline and stressor conditions) may reflect different types of stressor (short duration 
vs. chase and restraint), as well as perception of the stressor, previous dive experience in free-range vs. aquarium animals, diet, and history of immune challenge.

\section{Objective 4: compare the effects of simulated dive exposures on cellular immune function in seals between stranding (stressor) and release (healthy).}

Catecholamines and cortisol decreased as expected between admit and release conditions, though this change was only statistically significant for norepinephrine. However, no significant changes in control measures (without pressure) of any immune function were detected between admit and release conditions.

Significantly different responses in cell function between admit and release conditions were detected only for phagocytosis. During admit conditions, no change or decreased function was observed, whereas release samples displayed general patterns of increased function. Changes measured in release samples were also smaller than admit samples. It is interesting to note that admit (stressed) conditions in phocids resembled the response of beluga cells, whereas release (healthy) conditions resembled the response observed in human cells. This may reflect dive adaptation of different species, and suggest that some species may be 'higher risk' for developing dive-related pathologies.

CD11b expression displayed significant increases only following the 30 minute and single 5 minute duration exposures for admit conditions. No significant pressure induced effects on CD11b expression were detected in release samples for any duration exposure, nor were there significant differences in response detected between admit and release conditions.

Both admit and release samples displayed pressure induced increases in IL2R expression, and no difference in response was detected between the two conditions. Too few samples were available to compare admit and release proliferation, however general decreased function during admit conditions was observed.

\section{IMPACT/APPLICATIONS}

This project has relevance to the Navy in understanding the effects of sound on marine mammals through physiology, diving and stress by specifically addressing the questions of how the marine mammal immune system functions in response to diving (i.e. increased pressure) and whether a stressor (e.g. sound) can alter that response. Two potential non-auditory results of sound exposure in marine mammals are 1) changes in behavior, including dive behavior and 2) physiological changes including a neuroendocrine stress response. Before it is possible to evaluate the potential for either of these consequences to affect marine mammal health, it is important and necessary to understand how the marine mammal immune system is adapted to the natural challenges of the aquatic environment, including those associated with diving. This study aimed to look at the impact of various depths, durations and descent/ascent speeds on marine mammal immune function under healthy and stressor conditions as a first step in understanding the likely complicated relationship between dive behavior, immune function and health. Moreover, this work provides the first data demonstrating the potential for anthropogenic stressors to alter the response of marine mammal immune cells to diving, either through eliciting behavioral changes or a physiological stress response. We have demonstrated functional changes in marine mammal immune cell responses following in vitro pressure exposures which varied 1) between species 2) between exposures of various durations, depths and periods of compression and decompression and 3 ) between healthy and physiologically challenging conditions. From this it is suggested that it is possible for anthropogenic activities to alter the response of immune 
cells to diving and thus impact marine mammal health. While the results may not be as apparent as mass strandings, sub-lethal consequences may include decreased fitness or increased susceptibility to disease and injury.

\section{RELATED PROJECTS}

Investigation of the Physiological Responses of Belugas to "Stressors" to Aid in Assessing the Impact of Environmental and Anthropogenic Challenges on Health, T.Romano, T. Spoon and S. Lamb (ONR \# N00014-11-1-0437). A portion of the samples for the project described above were obtained from this related project.

\section{REFERENCES}

Schmitt, T.L., St Aubin, D.J., Schaefer, A.M., Dunn, J.L. 2010. Baseline, diurnal variations and stress induced changes of stress hormones in 3 captive beluga whales, Delphinapterus leucas. Mar. Mam. Sci. 26, 635-647.

Spoon, T. and Romano, T.A. 2012. Neuroimmunological response of beluga whales (Delphinapterus leucas) to translocation and social change. Brain Behav. Immunol. 26, 122-131.

\section{PUBLICATIONS}

Thompson, L.A. 2014. The Combined Influence of Diving Physiology and Stressors on Immune Cell Function in a Deep Diving Monodontid and Three Shallow Diving Phocid Species. PhD Dissertation, University of Connecticut.

\section{HONORS/AWARDS/PRIZES}

2014 Laura Thompson, Mystic Aquarium, Student Travel Award for travel to the International Association for Aquatic Animal Medicine Conference, Gold Coast, Australia

2014 Laura Thompson, Mystic Aquarium, Student Presentation Award, International Association for Aquatic Animal Medicine, Gold Coast, Australia 